\title{
A NEW GENUS OF THE FEATHER MITE FAMILY PROCTOPHYLLODIDAE (ACARIFORMES: ANALGOIDEA) FROM WOODCREEPERS (PASSERIFORMES: FURNARIIDAE: DENDROCOLAPTINAE) IN THE NEOTROPICS
}

\author{
Sergey V. Mironov ${ }^{1^{*}}$ and Sergio Bermúdez ${ }^{2}$
}

\author{
${ }^{1}$ Department of Parasitic Arthropods, Zoological Institute, Russian Academy of Sciences, \\ Saint Petersburg, Russia \\ ${ }^{2}$ Departamento de Investigación en Entomología Médica, Instituto Conmemorativo Gorgas de \\ Estudios de la Salud, Panamá, Panama \\ *corresponding author; e-mail: sergei.mironov@zin.ru
}

\begin{abstract}
A new feather mite genus Dendrocolaptobius gen. n. belonging to the Nycteridocaulus generic group (Proctophyllodidae: Proctophyllodinae) is described. The genus includes two species associated with woodcreepers (Furnariidae: Dendrocopaptinae): Dendrocolaptobius cuneiformis (Mironov, 2017) comb.n. previously described from Sittasomus griseicapillus (Vieillot) in Costa Rica; and D. lepidocolapti sp.n. described herein from Lepidocolaptes souleyetii (Lafresnaye) in Panama. The new genus Dendrocolaptobius is clearly distinguished from the other genera of the Nycteridocaulus group in having an inverted genital arch and enlarged bow-shaped basal sclerite in males and the copulatory opening situated dorsally on the lobar region in females.
\end{abstract}

KEY WORDS: Analgoidea, Proctophyllodidae, Dendrocolaptobius, systematics, Dendrocolaptinae, Panama.

DOI: 10.21684/0132-8077-2020-28-1-29-38

\section{INTRODUCTION}

Woodcreepers (Furnariidae: Dendrocolaptinae) are a subfamily of arboreal suboscine passerines widely distributed throughout the Neotropical region. This bird group was previously considered a distinct family Dendrocolaptidae (e.g., Howard and Moore 1991), but the recent research places them as a monophyletic subfamily of the ovenbirds (Passeriformes: Furnariidae) (Irestedt et al. 2009; Moyle et al. 2009; Derryberry et al. 2011). The dendrocolaptines currently contain around 57 species in 16 or more genera (Gill and Donsker 2018). They superficially resemble treecreepers (Passeriformes: Certhiidae) and woodpeckers (Piciformes: Picidae) both morphologically and ecologically, but these similarities are due to convergent evolution.

The feather mite fauna associated with this group of passerines is almost completely unexplored, except for the representatives of the family Proctophyllodidae (Acariformes: Analgoidea). In a series of taxonomic papers, Kudon (1982a-e) described the new proctophyllodid genus Platyacarus Kudon, 1982 (Proctophyllodinae) with 12 new species from the representatives of Dendrocolaptinae and analyzed their host associations. Subsequent investigations by other researchers produced descriptions of seven more Platyacarus species, among which five were also from woodcreepers, and two were from a different furnariid subfamily - the leaftossers (Sclerurinae) (Hernandes et al. 2007; Hernandes and Valim 2014; Mironov et al. 2017).
The genus Platyacarus represents one of two major lineages (generic groups) of proctophyllodines associated with suboscine passerines in the Neotropical region (Klimov et al. 2017). This generic group, also including the genera Tanyphyllodes Atyeo, 1966 and Tyranniphyllodes Hernandes, Valim and Mironov, 2007, is restricted to birds of the clade Furnariida (Atyeo 1966a; Hernandes et al. 2007; Mironov and González-Acuña 2009).

The second major lineage is the Nycteridocaulus generic group, which currently includes 31 species in seven genera: Anisophyllodes Atyeo, 1967, Atrichophyllodes Hernandes, Pedroso and Mironov, 2007, Armophyllodes Mironov and Bermúdes, 2018, Diproctophyllodes Atyeo, 1966, Hemipterodectes Berla, 1959, Nycteridocaulus Atyeo, 1966, and Rupicolacarus Atyeo, 1972 (Berla 1959; Atyeo 1966b, 1967, 1969, 1972; Atyeo and Gaud 1968; Hernandes et al. 2007; Hernandes and Valim 2014; Mironov et al. 2017; Mironov and Bermúdes 2018). In contrast to the Platyacarus group, the majority of representatives of the Nycteridocaulus group are associated with suboscines of the clade Tyrannida, with a few species known from oscine passerines of the families Parulidae and Troglodytidae. Only one species of the second group-Anisophyllodes cuneiformis Mironov, 2017-was described from a representative of Dendrocolaptinae, the Olivaceous Woodcreeper, Sittasomus griseicapillus (Vieillot) in Costa Rica. 
In the present paper we establish a new proctophyllodine genus Dendrocolaptobius gen. n. belonging to the Nycteridocaulus group and including two species: A. cuneiformis and one newly described species from the Streak-headed Woodcreeper, Lepidocolaptes souleyetii (Lafresnaye), in Panama.

\section{MATERIALS AND METHODS}

The material used in the present work was collected during our parasitological survey in central and western Panama (Colón and Chiriquí Provinces) in April 2016. The birds were captured with mist-nets placed near the edge of tropical rainforest, identified and checked for the presence of ectosymbionts. The feather mites were taken from live birds under a stereomicroscope (magnification $\times 10-20$ ) with a preparation needle or fine forceps and placed in tubes with $96 \%$ ethanol. After this processing taking 5-10 minutes, the captured birds were released into the wild. In the laboratory, the feather mites were mounted on slides in Hoyer's medium according to the standard technique for small acariform mites (Krantz and Walter 2009). The investigation of mite specimens and drawings were made using a Leica DM 2500 light microscope equipped with differential interference contrast (DIC) and a camera lucida.

The description of the new species and techniques for measuring morphological structures follow the current formats elaborated for proctophyllodid mites (Mironov 2006, 2012, 2017; Hernandes et al. 2007; Mironov and González-Acuña 2009; Hernandes 2014; Mironov et al. 2017). General morphological terms and idiosomal chaetotaxy follow Gaud and Atyeo (1996) with minor corrections for coxal setation by Norton (1998), and the leg chaetotaxy follows Grandjean (1939). All measurements are in micrometers $(\mu \mathrm{m})$. The taxonomic system and both common and scientific names of birds follow Gill and Donsker (2018).

The abbreviations used in collection numbers and depository designations are as follows: BMOC and UMMZ - Museum of Zoology of the University of Michigan (Ann Arbor, USA); ZISP-Zoological Institute of the Russian Academy of Sciences (Saint-Petersburg, Russia).

\section{SYSTEMATICS}

Family Proctophyllodidae Trouessart and Mégnin, 1884

Subfamily Proctophyllodinae Trouessart

and Mégnin, 1884

Genus Dendrocolaptobius Mironov and

Bermúdez sp.n.
Type species: Anisophyllodes cuneiformis

Mironov, 2017 (in: Mironov et al. 2017).

Diagnosis. Both sexes. Moderately elongated proctophyllodines. Prodorsal shield entire, covering almost the entire surface of the prodorsum, with anterolateral extensions, and with posterior obliquely angled. Vertical setae ve rudimentary, represented by alveoli. Scapular setae $s i$ and se situated on prodorsal shield and arranged in transverse line. Humeral shields well-developed dorsally, encompassing bases of setae $c p$, setae $c 2$ on margin of these shields. Subhumeral setae $c 3$ lanceolate. Epimerites I free, with posterior ends slightly divergent. Full set of hysterosomal setae occurring in proctophyllodines present. Solenidion $\sigma$ of genu I longer than solenidion $\omega 3$ of tarsus I. Tarsi I and II with 3 ventral setae, seta $w a$ slightly anterior to setae $l a$ and $r a$ on these tarsi. Segments of legs I and II without processes or other modifications.

Male. Hysteronotal shield covering almost all hysterosoma. Opisthosoma strongly attenuate posteriorly, roughly triangular in shape (Fig. 1A). Opisthosomal lobes small, represented by small semi-ovate extensions on the posterior end of opisthosoma, separated by very narrow terminal cleft, with narrow terminal lamellae along posterolateral margin of lobes. Supranal concavity present. Setae $h 3$ shorter than macrosetae $h 2$. Setae $h 1$ close to transverse levels of setae $p s 2$ and $h 2$. Coxal fields I-IV open, without extensive sclerotized areas. Genital organ at level of trochanters IV; genital arch inverted (i.e. its apex in normal position directed posteriorly), with thick bow-shaped branches; aedeagus sword-shaped and longer than genital arch; basal sclerite thick, bow-shaped, comparable in width to width of genital arch, occupying anterior position in genital apparatus (Figs. 1B, 4A, B). Genital papillae situated on a pair of bow-shaped plates (derivatives of paragenital apodemes) at anterior margin of genital apparatus. Pregenital apodemes present, situated between epimerites IIIa and genital apparatus. Opisthoventral shields present. Adanal apodemes present, fused to posterior margins of opisthoventral shields. Adanal shields variable in form, situated anterolateral to adanal suckers. Adanal suckers cylindrical, corolla dentate. Legs IV much thicker than legs III. Tarsus IV with apical claw-like process, without ventral extension at base of seta $w$, modified setae $d$ and $e$ button-like.

Female. Lobar region of opisthosoma clearly separated from remaining part of hysterosoma, 
opisthosomal lobes well developed, with terminal appendages. Anterior hysteronotal and lobar shields separated by narrow band of striated tegument. Lobar shield entire. Supranal concavity absent. Macrosetae $h 2$ strongly thickened basally, with filiform apex. Epigynum thick, semicircular, free from epimerites IIIa. Translobar apodemes present, fused to each other anterior to terminal cleft. Copulatory opening dorsal, situated on lobar shield or on striated tegument between hysteronotal and lobar shields (Figs. 2A, 3E). Solenidion $\varphi$ of tibia IV distinctly shorter that than $\varphi$ of tibia III.

Differential diagnosis. The new genus Dendrocolaptobius gen. $n$. belongs to the Nycteridocaulus generic group (Klimov et al. 2017) characterized by free epimerites I with divergent or rarely almost parallel posterior ends in both sexes. In the general appearance and especially by the form of the body, males of Dendrocolaptobius resemble those of the genus Anisophyllodes in having the hysterosoma strongly attenuate posteriorly and having a pair of small opisthosomal lobes. Nevertheless, mites of the new genus are readily distinguished from all other genera of the Nycleridocaulus generic group by unique features of genitalia, both in males and females. In males of Dendrocolaptobius species, the genital arch in normal position is inverted, i.e. its apex is directed posteriorly (Fig. 4A-D). Additionally, in males, the basal sclerite of the genital apparatus is strongly developed and represented by a big thick bow, which is comparable in width to the genital arch. In males of the other members of the Nycteridocaulus group, the genital arch is shaped as a common short or a double recurved bow and with its apex directed anteriorly. The basal sclerite in males of these genera is a small trapezoidal sclerite barely distinct between or behind the branches of the genital arch (Fig. 4F-H). In females of Dendrocolaptobius species, the copulatory opening is situated dorsally on the lobar region of opisthosoma, while in females of the other genera, this opening is situated terminally in the anterior end of the terminal cleft or subterminally, on the ventral side of opisthosoma between the anal opening and the anterior margin of the cleft.

Hosts. Furnariidae: Dendrocolaptinae.

Species included. Dendrocolaptobius cuneiformis (Mironov, 2017) comb.n. and D. lepidocolapti sp.n.

Etymology. The name is a contraction of the host subfamily Dendrocolaptinae and bios (Gr. life).

\section{Dendrocolaptobius lepidocolapti Mironov and Bermúdez sp.n.}

(Figs. 1-3, 4A and B)

Type material. Male holotype (BMOC 200303-014), 2 male and 10 female paratypes from Lepidocolaptes souleyetii (Lafresnaye, 1849) (Passeriformes: Furnariidae), Panama, Chiriquí Province, La Amistad International Park, Las Nubes Ranger Station, $8^{\circ} 53^{\prime} 38^{\prime \prime} \mathrm{N}, 82^{\circ} 36^{\prime} 54^{\prime \prime} \mathrm{W}, 29$ April 2016, coll. S. V. Mironov.

Depository. Depository. Holotype, 1 male and 5 female paratypes - UMMZ, remaining paratypes (ZISP 8803-8808)-ZISP.

Description. Male (holotype, range for 2 paratypes in parentheses). Idiosoma, length $\times$ width, 335 (340-345) $\times 185(185-190)$, length of hysterosoma 215 (215-220). Prodorsal shield: antero-lateral extensions short and acute, lateral margins without incisions, posterior angles obliquely angled, posterior margin almost straight, setae ve rudimentary, anterior part with numerous longitudinal dash-like lacunae, length along midline 95 (95-105), width at posterior margin 125 (125-145). Scapular setae se separated by 80 (75-80). Setae $c 2$ in anteromesal angles of humeral shields. Setae $c p$ on humeral shield. Setae $c 3$ lanceolate, 22 (20-22) long, about 5 width. Distance between prodorsal and hysteronotal shields along midline 35 (35-40). Hysteronotal shield: 210 (210-215) long, 125 (125-130) wide; anterior margin straight or slightly concave; anterior angles acute, surface with numerous longitudinal dash-like and narrowly triangular lacunae in anterior three quarters and with ovate lacunae in posterior quarter (Fig. 1A). Setae $c l$ on anterior margin of hysteronotal shield. Opisthosoma noticeably attenuate posteriorly, roughly triangular in general shape; opisthosomal lobes small, with oblique and slightly convex posterolateral margins bearing narrow and rounded terminal lamellae, about 5 in greatest length and about 20 in width. Terminal cleft between lobes slitshaped, anterior end of the cleft not extending to level of setae $h 3$, length from anterior end to posterior margin of terminal lamellae 15 (15-16), greatest width 4 (3-4). Supranal concavity closed, shaped as inverted teardrop, distance from anterior end of this concavity to bottom of terminal cleft 32 (28-35). Setae $h 2$ situated on small lateral extensions of opisthosoma, setae $h 3$ posterior to them on small lateral convexities. Setae $p s 1$ minute spiculiform, situated on lateral margins of terminal cleft, noticeably posterior to level of setae $h 3$. 


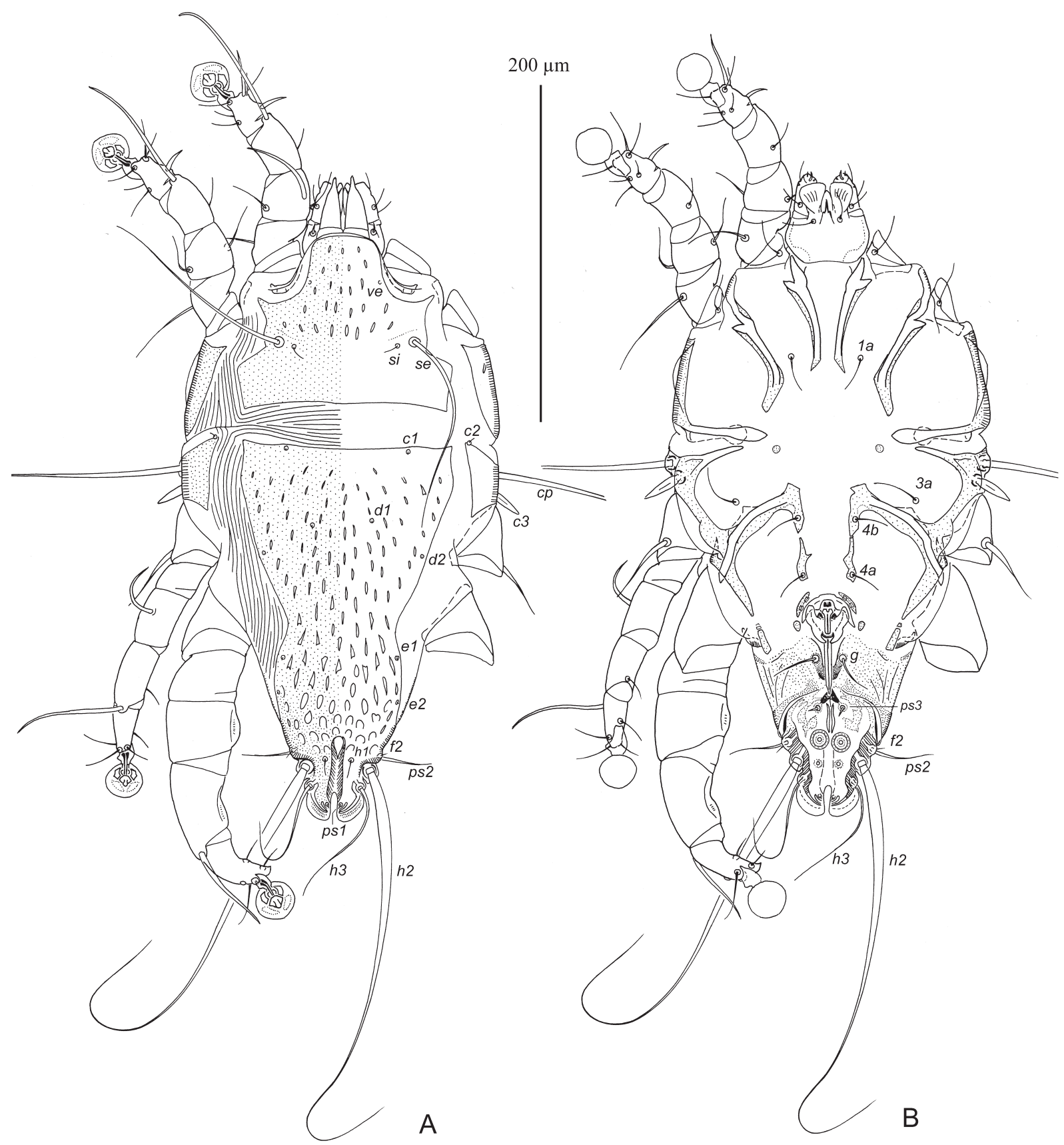

Fig. 1. Dendrocolaptobius lepidocolapti sp.n., male. A—dorsal view, B—ventral view.

Distance between dorsal setae: $c 2: d 262(65-70)$, $d 2: e 270$ (70-78), e2:h3 55 (52-55), h2:h2 37 (38-40), h3:h3 30 (27-32), ps2:ps2 50 (50-52), h1:h2 5 (5-8), h3:ps1 10 (10-12), d1:d2 20 (1820), e1:e2 18 (20-24).

Epimerites I free, well separated, with posterior tips slightly divergent, without large sclerotized areas around them; epimerites II with narrow sclerotized fields (Fig. 1B). Epimerites IVa small, rudimentary sclerite rEpIIa present. Genital arch inverted (directed posteriorly), with pair of rounded hook-like apical extensions, 20 (20-22) long and 25 (25-28) wide; basal sclerite thick, bowshaped (crescent-shaped), 30 (30-33) wide (Fig. 4A). Aedeagus sword-shaped, 32 (30-32) long, with tip reaching anterior end of anal opening. Distance from anterior margin of genital apparatus to lobar apices 120 (120-125). Genital papillae of each side on small bow-shaped plates (paragenital apodemes) at anterior margin of basal sclerite. Pregenital apodemes represented by a pair of longitudinal sclerites (one or both of them can be interrupted), with anterior ends fused with inner tips of epimerites IIIa, and with posterior ends extending 

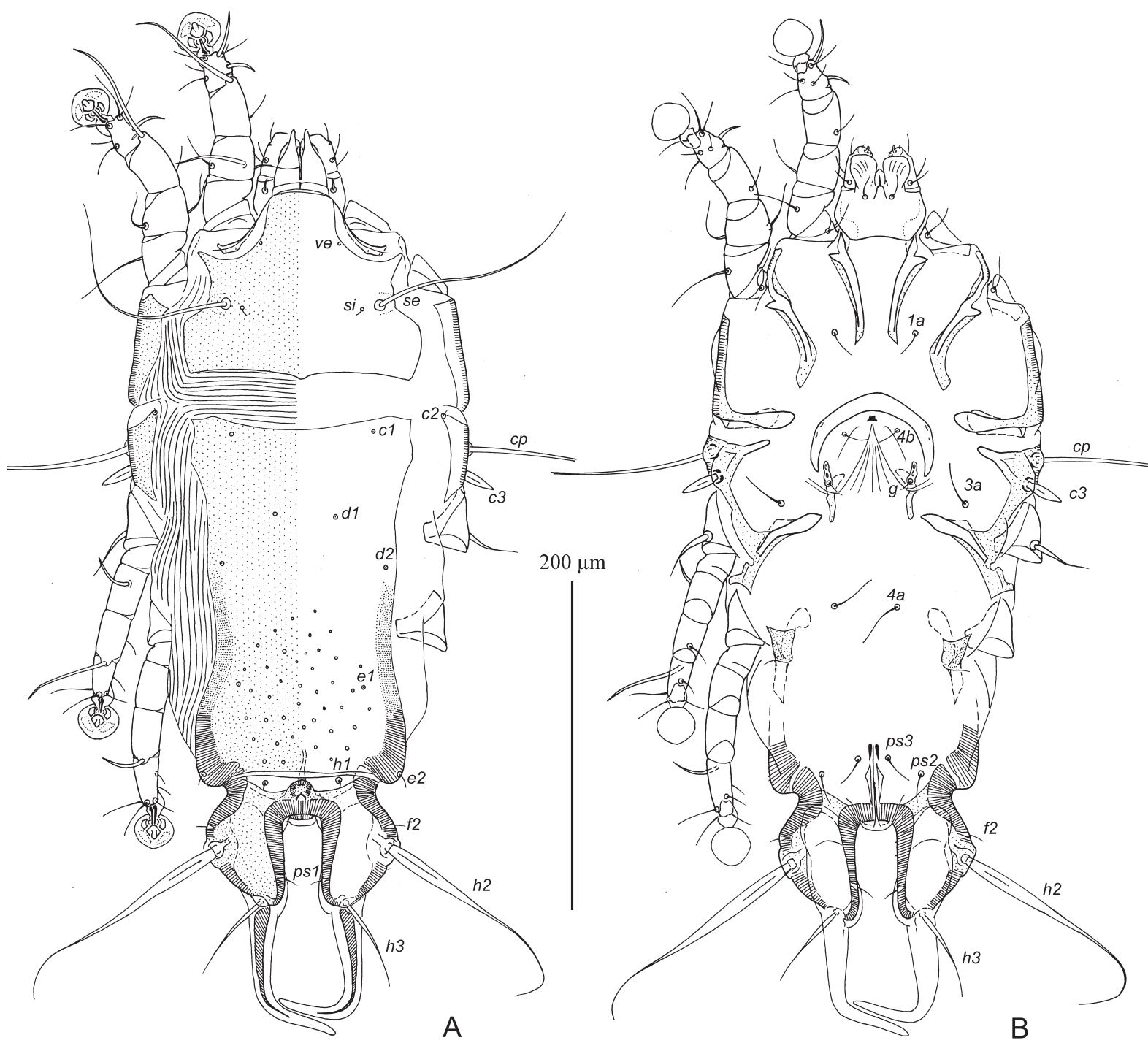

Fig. 2. Dendrocolaptobius lepidocolapti sp.n., female. A-dorsal view, B-ventral view.

to bases of setae $4 a$; setae $4 b$ situated on anterior parts of these apodemes. Additional paragenital sclerites ovate, situated near tips of basal sclerite. Opisthoventral shields occupying most lateral areas of opisthosoma, fused at midline to each other and posteriorly with adanal apodemes forming entire shield between genital apparatus and anal field; anterior margin of this complex shield with deep U-shaped incision encompassing aedeagus. Adanal membranes narrow. Adanal suckers 11 (10-11) in diameter, corolla with $12-15$ barely distinct denticles. Adanal shields of complicated uneven form, fused anteriorly with adanal apodemes; one unpaired median fragment of triangular form heavily sclerotized. Setae $p s 3$ short spiculiform, situated on small ovate fragments of adanal shields. Cupules $i h$ situated at level of setae $h 2$ and surrounded by sclerotized areas. Distance between ventral setae: $3 a: 4 b 13(10-13), 4 b: 4 a 32(30-32)$, 4a:g 48 (42-48), g:g 15 (15-16), g:ps3 28 (28-30), ps3:ps3 15 (15-18), ps3:h3 40 (40-42).

Femora I and II without distinct ventral ridge. Solenidion $\sigma$ I 2-2.5 times longer than genu I and situated at midlevel of this segment (Fig. 3A, B). Solenidion $\sigma$ of genu III situated at midlevel of segment. Legs IV much thicker than legs III, with tarsus and distal part of tibia IV extending beyond level of terminal lamellae. Femur IV with distinct ventral ridge, and tibia IV with narrow ventral ridge. Tarsus IV 36 (36-38) long, with rounded apex and apicoventral claw-like process near base of seta $w$; modified setae $d$ button-like, situated in distal half of this segment (Fig. 3D, E). Setae $d, f$ of tarsi II and III subequal in length. Length of solenidia: $\sigma$ I 40 (35-38), $\sigma$ III 30 (30-32), $\varphi$ IV 42 (38-42). 


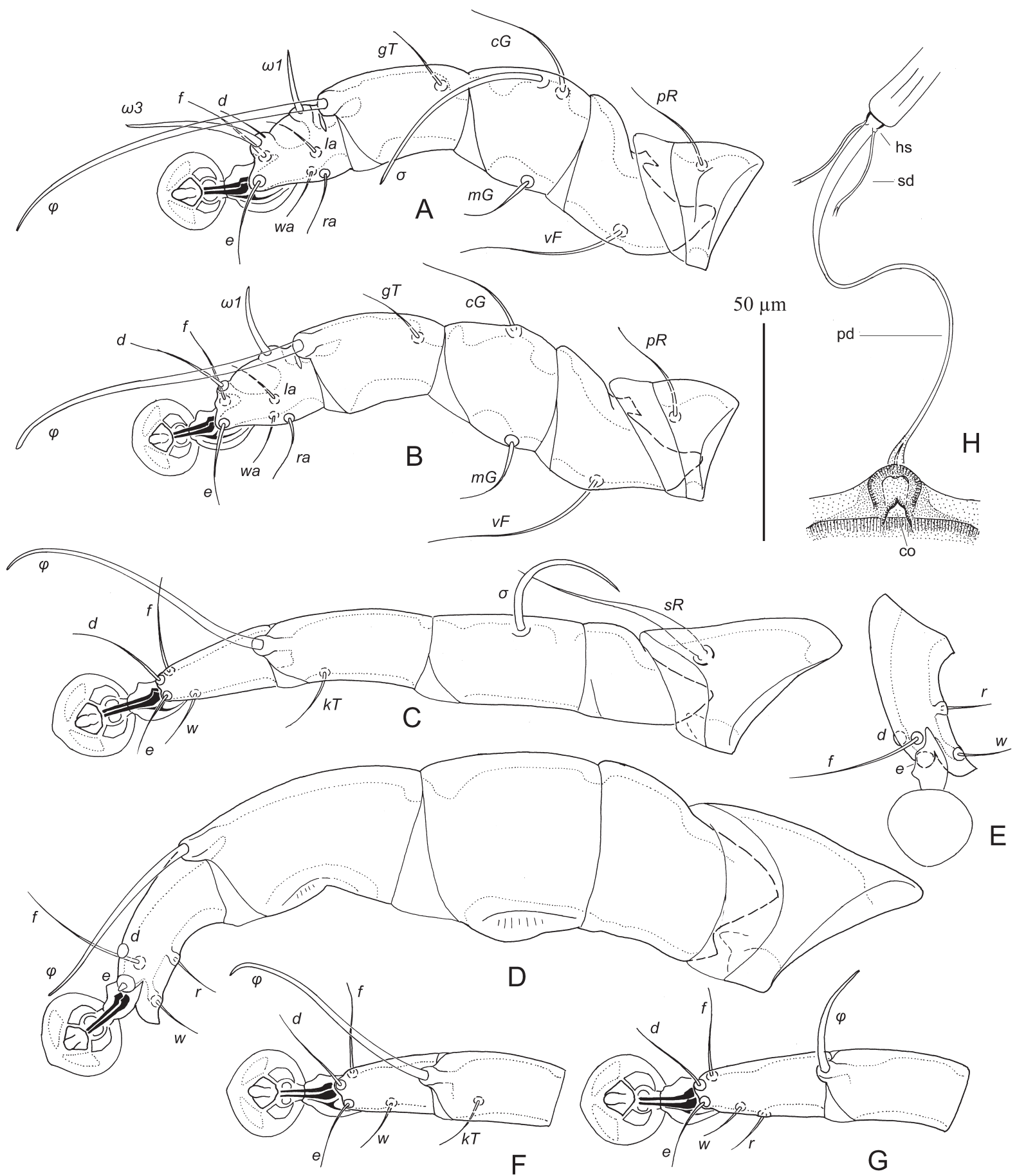

Fig. 3. Dendrocolaptobius lepidocolapti sp.n., details. A-D — dorsal view of legs I-IV of male, respectively; E-tarsus IV of male, ventral view; F and G-tibia and tarsus III and IV of female, respectively; H—spermatheca and spermaducts. Abbreviations: co — copulatory opening, hs — head of spermatheca, pd — primary spermaduct, sd — secondary spermaduct.

Female (range for 10 paratypes). Idiosoma, length $\times$ width, $400-415 \times 195-205$, length of hysterosoma 270-290. Prodorsal shield: anterolateral extensions acute, lateral margins entire, posterior margin with blunt-angular median extensions and with a pair of wide and shallow concavities, surface without ornamentation, 100-110 in length and $135-145$ in width. Setae ve rudimentary. Setae se separated by $85-95$. Setae $c 2$ in antero-mesal angles of humeral shields. Setae $c 3$ lanceolate, 20-24 long, about 5 wide. Setae $c p$ on humeral shields. Distance between prodorsal and hysteronotal shields along median line 30-35. Hysteronotal shield completely split into anterior and lobar parts. Anterior hysteronotal shield: $195-215$ long and 120-135 wide; anterior margin concave, anterior angles acute, 


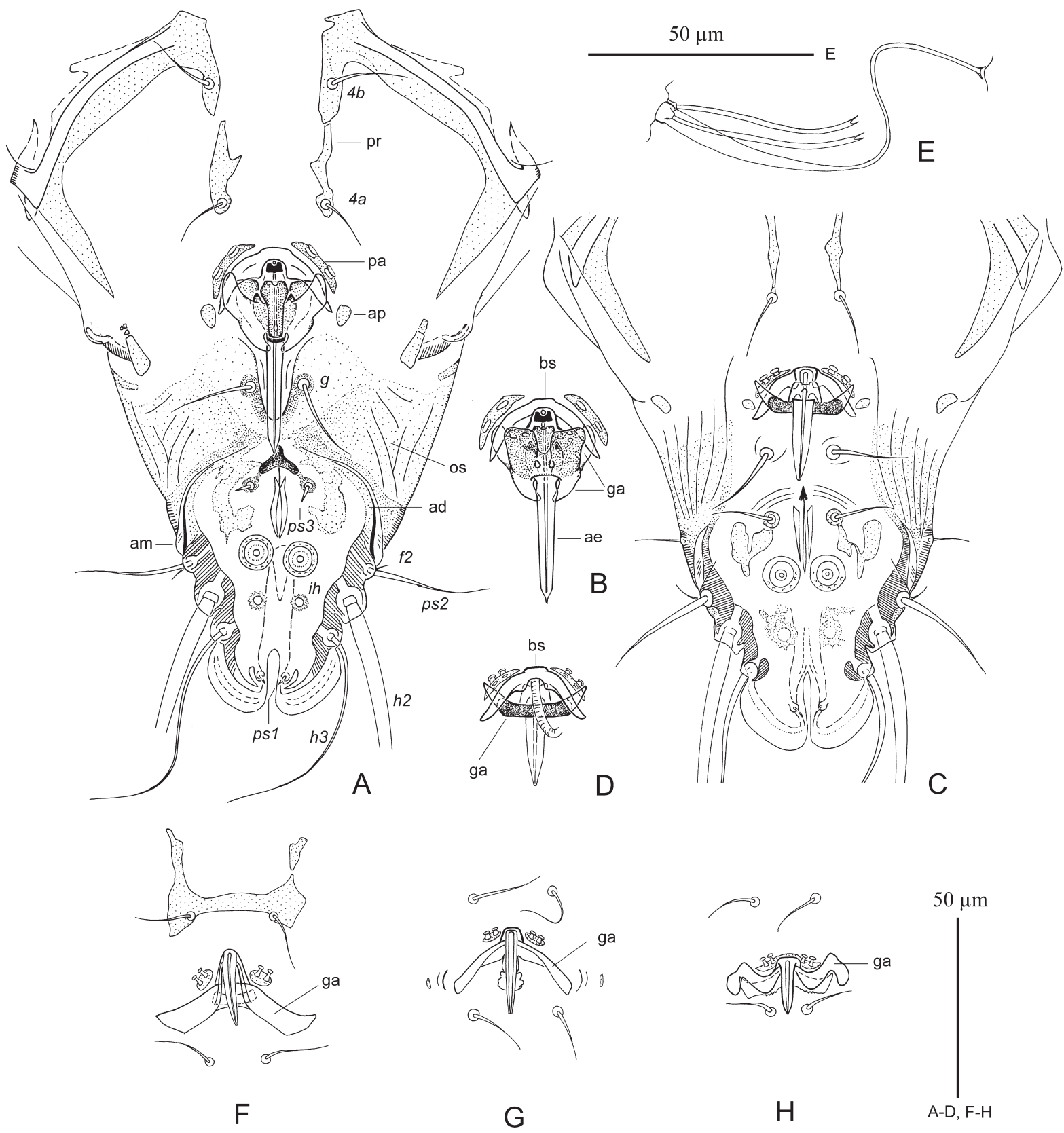

Fig. 4. Details of genital structures in the Nycteridocaulus generic group. A-Dendrocolaptobius lepidocolapti, sp.n. ventral view of male opisthosoma; B - same, dorsal view of male genital apparatus, $\mathrm{C}-D$. cuneiformis (Mironov, 2017) ventral view of male opisthosoma; D — same, dorsal view of male genital apparatus; E — same, spermatheca and spermaducts; F-Anisophyllodes pipromorphae Atyeo, 1967, ventral view of male genital apparatus; G-Nycteridocaulus hylophylax Mironov, 2017, ventral view of male genital apparatus; H-Nycteridocaulus attila Mironov, 2017, ventral view of male genital apparatus. Abbreviations: ad — adanal apodeme, ae — aedeagus, am — adanal membrane, ap additional paragenital sclerite, bs—basal sclerite, ga—genital arch, pa—paragenital apodeme, pr—pregenital apodeme.

posterior margin straight, posterior half with numerous small, sparsely disposed, circular lacunae (Fig. 2A). Setae $c l$ on anterior margin of hysteronotal shield. Lobar region: anterior margin with median convexity, bearing heavily sclerotized tubercle with copulatory opening; greatest length of region 70 75 , greatest width 110-120 (Fig. 3H). Terminal cleft parallel-sided, almost rectangular in shape, $45-55$ in length and 25-32 in width. Setae $h 1$ inserted on striated tegument between the anterior hysteronotal and lobar shields. Setae $h 2$ strongly thickened basally, with filiform apical part, 110-130 in length, 6-7 in width; setae $h 352-55$ in length. Setae $h 1$ and $f 2$ in trapezoidal arrangement. Distance between dorsal setae: $c 2: d 2$ 84-88, $d 2: e 2$ 110-120, e2:h2 41-48, h2:h3 30-34, h1:h2 38-43, d1:d2 
24-30, e1:e2 46-50, h1:h1 40-45, h2:h2 100-110, h2:ps1 17-20.

Epimerites I as in male; epimerites I and II with narrow sclerotized fields. Epimerites IVa present, with long anterior and posterior subtegumental apodemes. Epigynum semicircular, thick, without lateral extensions, 43-50 in length, 70-80 in width, tips extending to level of posterior pair of genital papillae (Fig. 2B). Genital papillae and seta $g$ of each side on small ovate sclerite. Setae $p s 2$ at level of anterior half of anal opening. Translobar apodemes fused to each other anterior to terminal cleft. Posterior flaps of anal opening slightly extending into terminal cleft. Head of spermatheca short, proximal part of primary spermaduct with ampuliform enlargement, secondary spermaducts 25-30 long (Fig. 3H). Distance between pseudanal setae: ps2:ps2 52-57, ps3:ps3 18-20, ps2:ps3 8-10.

Legs I and II as in male. Solenidion $\sigma$ of genu III situated in basal part of this segment. Legs IV with ambulacral disc extending to level of setae $h 2$. Solenidion $\varphi$ of tibia IV slightly shorter than corresponding tarsus. Setae $d$ of tarsi II-IV subequal in length to corresponding setae $f$. Length of solenidia: $\sigma \mathrm{I} 38-42, \sigma \mathrm{III} 22-27, \varphi$ III 48-52, $\varphi$ IV 26-28.

Differential diagnosis. Dendrocolaptobius lepidocolapti sp.n. differs from the type species of the genus-D. cuneiformis (Mironov, 2017) (see below) - by several features: in males, the posterior part of the prodorsal shield lacks any ornamentation, the anterior part of hysteronotal shield bears longitudinal dash-shaped lacunae, the opisthoventral shields are fused to each other along midline into an entire ventral shield with deep U-shaped incision on the anterior margin, the aedeagus is 30-32 long, setae $g$ are spiculiform, and femur IV has a well-developed ventral ridge; in females, the prodorsal shield and anterior half of hysteronotal shield lack ornamentation, and the copulatory opening is situated on the heavily sclerotized tubercle of the lobar shield. In males of $D$. cuneiformis, the entire surface of the prodorsal shield bears small elongated and polygonal lacunae, the anterior part of hysteronotal shield bears triangular and polygonal lacunae, the opisthoventral shields are not fused, the aedeagus is 20-24 long, setae $g$ are filiform, and femur IV does not have a ventral ridge; in females, the entire surface of the prodorsal shield and hysteronotal shields bears small ovate and dash-like lacunae, and the copulatory opening is situated on the soft tegument near the posterior margin of the hysteronotal shield.
Etymology. The specific epithet is derived from the generic name of the type host and is a noun in the genitive case.

\section{Dendrocolaptobius cuneiformis (Mironov, 2017) comb.n.}

\author{
(Fig. 4C-E)
}

Anisophyllodes cuneiformis Mironov, 2017, in: Mironov et al. 2017: 67, fig. 37-39.

Material examined. Male holotype (ZISP 6400), 7 male and 7 female paratypes from Sittasomus griseicapillus (Vieillot, 1818) (Furnariidae), Costa Rica, Tapantí National Park, Sector Tapantí, Cordillera de Talamaca Mts., $09^{\circ} 46^{\prime} \mathrm{N}, 83^{\circ} 47^{\prime} \mathrm{W}, 2$ August 2009, coll. I. Literak, O. Sychra and M. Capek.

This species, originally described as a member of the genus Anisophyllodes, is known only from the Olivaceous Woodcreeper, Sittasomus griseicapillus, in Costa Rica (Mironov et al. 2017).

\section{ACKNOWLEDGEMENTS}

The authors thank L. Domínguez and S. Torres (Instituto Gorgas, Panama City, Panama) for their major help in capturing the animals and collecting ectoparasites during our field trip in 2016 and Dr. Heather C. Proctor (University of Alberta, Edmonton, Canada) for critically reviewing the manuscript. The capturing of hosts and collecting of symbionts were performed according to the licenses (No. SE/A-100-2015, DAPVS-0743-2016) issued by the Environment National Ministry of Panama. The taxonomic part of this study was supported by the Russian Foundation for Basic Research (No. 20-04-00500a) for SM, and the field investigation was funded by the UNACHI grant (No. 184-CN-01-A095-04-2013) for SB.

\section{REFERENCES}

Atyeo, W.T . 1966a. Two new genera of feather mites (Acarina: Proctophyllodidae). Journal of the Kansas Entomological Society, 39: 473-480.

Atyeo W.T. 1966b. A new genus and six new species of feather mites primarily from Tyranni (Acarina: Proctophyllodidae). Journal of the Kansas Entomological Society, 39: 481-492.

Atyeo, W.T. 1967. Two new feather mite genera with polymorphic males (Analgoidea: Proctophyllodidae). Journal of the Kansas Entomological Society, 40: 465-471.

Atyeo, W.T. 1969. Redescription of Anisophyllodes intermedius (Trouessart and Neumann), 1888, new 
combination (Acarina: Proctophyllodidae). Journal of the Georgia Entomological Society, 4: 153-155.

Atyeo, W.T. 1972. A new genus of feather mites (Analgoidea: Proctophyllodidae) from cocks-of-the-rock (Aves: Rupicolidae). Boletim do Museu nacional de Rio de Janeiro, n. s., Zoologia, 285: 1-6.

Atyeo, W.T. and Gaud, J. 1968. Two feather mite genera (Analgoidea, Proctophyllodidae) from birds of the families Oxyruncidae and Pipridae (Passeriformes, Tyranni). Bulletin of the University of Nebraska State Museum, 8: 209-215.

Berla, H.F. 1959. Analgesoidea neotropicais. VI. Um novo gênero de acarinos plumícolas (Acarina, Proctophyllodinae), hóspede de Oxyruncidae (Aves, Passeriformes). Studia Entomologica, 2: 31-32.

Derryberry, E.P., Claramunt, S., Derryberry, G., Chesser, R. T., Cracraft, J., Aleixo, A., Pérez-Emán, J., Remsen Jr., J.V. and Brumfield, R. T. 2011. Lineage diversification and morphological evolution in a large-scale continental radiation: the Neotropical ovenbirds and woodcreepers (Aves: Furnariidae). Evolution, 65(10): 2973-2986.

Gaud, J. and Atyeo, W.T. 1996. Feather mites of the World (Acarina, Astigmata): the supraspecific taxa. Musée Royal de l'Afrique Centrale, Annales, Sciences Zoologiques, 277, Pt. 1: 1-193; Pt. 2: 1-436.

Gill, F. and Donsker, D. (Eds.). 2019. IOC World Bird List (v 9.2). DOI: 10.14344/IOC.ML.9.2. http:// www.worldbirdnames.org/

Grandjean, F. 1939. La chaetotaxie des pattes chez les Acaridiae. Bulletin de la Société zoologique de France, 64: 50-60.

Hernandes, F.A. 2014. Three new proctophyllodine feather mites (Acari: Proctophyllodidae) from passerines in Brazil (Aves: Passeriformes). Journal of Natural History, 48: 185-202.

Hernandes, F.A. and Valim, M.P. 2014. On the identity of two species of Proctophyllodidae (Acari: Astigmata: Analgoidea) described by Herbert F. Berla in Brazil, with a description of Lamellodectes gen. nov. and a new species. Zootaxa, 3794: 179-200.

Hernandes, F. A., Valim, M.P. and Mironov, S. V. 2007. Two new genera and five new species of the feather mite subfamily Proctophyllodinae (Astigmata: Proctophyllodidae) from suboscine birds in Brazil. Journal of Natural History, 41: 2653-2681.

Howard, R. and Moore, A. 1991. A Complete Checklist of the Birds of the World. $2^{\text {nd }}$ Edition. Academic Press, London. 622 pp.

Irestedt, M., Fjeldså, J., Dalen, L. and Ericson, P.G.P. 2009. Convergent evolution, habitat shifts and variable diversification rates in the ovenbirdwoodcreeper family (Furnariidae). BMC Evolutionary Biology, 9: 268.
Klimov, P.B, Mironov, S.V. and OConnor, B.M. 2017. Detecting ancient co-dispersals and host shifts by double dating of host and parasite phylogenies: application in proctophyllodid feather mites associated with passerine birds. Evolution, 71-10: 2381-2397.

Krantz, G. and Walter, D. (Eds.) 2009. A Manual of Acarology. $3^{\text {rd }}$ edition. Texas Tech University Press, Lubbock. 807 pp.

Kudon, L.H. 1982a. Platyacarus, a new genus of feather mites (Acarina: Proctophyllodidae). Journal of the Georgia Entomological Society, 17: 337-346.

Kudon, L.H. 1982b. Descriptions of three new species in the genus Platyacarus Kudon (Acarina: Proctophyllodidae). Journal of the Georgia Entomological Society, 17: 525-530.

Kudon, L.H. 1982c. New feather mites from the genus Platyacarus (Acarina: Proctophyllodidae). Journal of the Georgia Entomological Society, 17: 531-536.

Kudon, L.H. 1982d. Four new species of feather mites from the genus Platyacarus (Acarina: Proctophyllodidae). Journal of the Georgia Entomological Society, 17: 537-544.

Kudon, L.H. 1982e. Host relationships of the feather mite genus Platyacarus Kudon (Acarina: Proctophyllodidae) with a key to the species. Journal of the Georgia Entomological Society, 17: 545-552.

Mironov, S. V. 2006. Feather mites of the genus Montesauria Oudemans (Astigmata: Proctophyllodidae) associated with starlings (Passeriformes: Sturnidae) in the Indo-Malayan region, with notes on systematics of the genus. Acarina, 14(1): 21-40.

Mironov, S.V. 2012. New species of the feather mite genus Proctophyllodes Robin, 1877 (Acari: Analgoidea: Proctophyllodidae) from European passerines (Aves: Passeriformes), with an updated checklist of the genus. Acarina, 20(2): 130-158.

Mironov, S.V. 2017. Two new feather mites of the genus Proctophyllodes Robin (Acari: Proctophyllodidae) from European passerines (Aves: Passeriformes). Systematic Parasitology, 94: 215-226.

Mironov, S.V. and Bermúdez, S. 2018. A new feather mite genus of the family Proctophyllodidae (Acariformes: Analgoidea) from the Olivaceus Flatbill Rhynchocyclus olivaceus (Passeriformes: Tyrannidae) in Panama. Systematic and Applied Acarology, 23(8): 1641-1655.

Mironov, S.V. and González-Acuña, D.A. 2009. Two new species of the feather mite subfamily Proctophyllodinae (Acari: Proctophyllodidae) from suboscine birds (Aves: Passeriformes) in Chile. Acarina, 17(2): 189-199.

Mironov, S. V., Literak, I., Sychra, O. and Capek, M. 2017. Feather mites of the subfamily Proctophyl- 


\section{S. V. Mironov and S. Bermúdez}

lodinae (Acari: Proctophyllodidae) from passerines (Aves: Passeriformes) in Costa Rica. Zootaxa, 4297(1): 1-105.

Moyle, R.G., Chesser, R.T., Brumfield, R.T., Tello, J.G., Marchese, D. J. and Cracraft, J. 2009. Phylogeny and phylogenetic classification of the ant- birds, ovenbirds, woodcreepers, and allies (Aves: Passeriformes: infraorder Furnariides). Cladistics, 25(4): 386-405.

Norton, R. 1998. Morphological evidence for the evolutionary origin of Astigmata (Acari: Acariformes). Experimental and Applied Acarology, 22: 559-594. 